\title{
Allogeneic CD34-positive E-rosetted T-cell Depleted Peripheral Blood Stem Cells
}

National Cancer Institute

\section{Source}

National Cancer Institute. Allogeneic CD34-positive E-rosetted T-cell Depleted Peripheral

Blood Stem Cells. NCl Thesaurus. Code C153885.

A preparation of CD34+ selected peripheral blood stem cells (PBSCs) that are depleted of

T-cells via erythrocyte rosetting (E-rosetting) and intended for allogeneic stem cell transplant. Administration of this particular preparation of CD34+E- T-cell depleted PBSCs may potentially reduce the occurrence of graft-versus-host disease (GvHD) without increasing the risk of graft failure or poor graft function 